Gut, 1973, 14, 418-430

\title{
The British Society of Gastroenterology
}

The spring meeting this year was held at the University Hospital of Wales, Cardiff, where the programme was arranged in two simultaneous sessions of free communications on 6 April and a final session of such papers on the afternoon of 7 April. The morning of 7 April was occupied by a symposium on 'Secretion of bile' in which invited speakers introduced each topic and finally formed a panel to answer questions from the audience. The speakers were G. Erlinger ('Secretion of bile'), K. Heaton ('Bile in the intestine-physiology'), R. Hermon Dowling ('Bile in the intestine-pathology'), N. Javitt ('Bile salts and cholestasis'), and Ian Bouchier ('Gallstones').

Abstracts of papers read at the meeting are printed below.

\section{Coagulation Studies in Acute Hepatic Failure}

J. S. TUCKER, I. L. WOOLF, B. E. BOYES, JEAN M. THOMSON, L. POLLER, AND I. W. DYMOCK (Departments of Medicine and Haematology, the University Hospital of South Manchester) It has been suggested recently that intravascular coagulation plays a major role in the haemorrhagic diathesis of acute hepatic failure and may adversely affect liver function. In view of our disappointing results with heparin therapy as suggested by Rake et al (1971) we sought to examine the relative roles of intravascular coagulation and synthetic failure by detailed clotting studies in five patients with this clinical syndrome. The diagnoses included acute viral hepatitis (four patients) and paracetamol overdosage (one patient).

In agreement with previous reports the prothrombin activity afforded a good prognostic index, being above $20 \%$ in the one patient who survived and below $15 \%$ in the other four.

Fibrin degradation product titres (FDP) were significantly raised in three patients suggesting the occurrence of intravascular coagulation but in only one was this associated with other classical features such as thrombocytopaenia or a disproportionate prolongation of the thrombin-fibrinogen time.

The levels of factor VII, which is not consumed in the process of intravascular coagulation, were profoundly depressed (less than 15\%) in four patients reflecting impaired hepatic synthesis. In one patient factor VII activity was not grossly depressed but there was a low factor V level, and, in the absence of evidence of intravascular coagulation in this case, presumably represented failure of hepatic synthesis.

The three patients with some evidence of intravascular coagulation were treated with intravenous heparin. One survived, with progressive diminution of the FDP titre and resolution of the other coagula- tion abnormalities by one week after therapy was instituted. It is not at all certain whether this treatment was responsible for her recovery since in this patient the prothrombin time was least prolonged and consequently there was a better prognosis from the outset.

It is concluded from this study that failure of hepatic synthesis of clotting factors has a more serious influence on the prognosis in acute hepatic failure than consumption of clotting factors through intravascular coagulation.

Reference
Rake, M. O. Shilkin, K. B., Winch, J., Flute, P. T., Lewis, M. L.
and Williams, R. (1971). Lancet, 2, 1215 .

Biliary Lipid Secretion in Health and in Cholelithiasis

T. C. NORTHFIELD AND A. F. HOFMANN (Gastroenterology Unit, Mayo Clinic, Rochester, Minnesota, USA) It is currently believed that cholesterol cholelithiasis in Caucasians is a hepatic disease (Small, 1972) involving production of abnormal bile, supersaturated with cholesterol (lithogenic) (Vlahcevic et al, 1970). This is attributed to a reduced secretion rate of bile acids and phospholipid, since bile acid pool size is reduced in gallstone patients (Swell et al, 1971). To test this, we measured bile acid pool size by isotope dilution, and the hourly output of biliary lipids during three meals and an overnight fast by a duodenal perfusion technique. In addition to polyethylene glycol, the perfusate contained labelled phospholipid and cholesterol in a sonicated sol as absorbable markers. Seven Caucasians with radiolucent gallstones were compared with seven carefully matched controls without gallstones. Bile acid pool size was inversely related 
to recycling rate $(\mathrm{P}<0.01)$, so that secretion rate remained constant. Total daily output of all three biliary lipids was similar in the two groups. In individual subjects, hourly measurements showed a linear relationship between bile acid and cholesterol output, but a sigmoid relationship between bile acid and phospholipid output. As a result, samples were consistently lithogenic at low bile acid outputs. Secretion of lithogenic bile occurred with equal frequency in both groups of subjects, especially during overnight fasting, and appears to be physiological.

\section{References}

Small, D. M. (1972). Postgrad. Med., 51, 187.

Vlahcevic, Z. R., Bell, C. C., and Swell, L. (1970). Gastroenterology, $59,62$.

Swell, L., Bell, C. C., and Vlahcevic, Z. R. (1971). Gastroenterology, 61, 716.

Enzyme Changes in Experimental Biliary Obstruction

A. KRYSZEWSKI, J. B. WHITFIELD, D. W. MOSS, AND G. NEALE (Departments of Medicine and Chemical Pathology, Royal Postgraduate Medical School, London) In patients with diseases affecting the biliary tract serum concentrations of alkaline phosphatase (ALP), 5'nucleotidase (5NT) and gammaglutamyltranspeptidase (GGT) are usually considered of equivalent diagnostic value even though they do not always behave identically (Phelan et al, 1971).

We have studied changes in hepatic and serum concentrations of the three enzymes in groups of rats following bile duct ligation. Hepatic ALP rose rapidly from $73 \pm 7$ to a maximum of $735 \pm 85$ $\mathrm{IU} / \mathrm{g}$ protein at 12 hours whereas $5 \mathrm{NT}$ and GGT did not increase until 48 hours after operation and then there was a slow rise over the next eight days (5NT from $64 \pm 5$ to $107 \pm 4 \mathrm{IU} / \mathrm{g}$ : GGT from $3 \cdot 7 \pm 0.3$ to $12 \cdot 5 \pm 1 \cdot 1 \mathrm{IU} / \mathrm{g}$ ).

In contrast, serum values of all three enzymes rose significantly in the first 12 hours after bile duct ligation and reached maximum values at 24 hours for ALP (from $238 \pm 13$ to $714 \pm 44 \mathrm{IU} / \mathrm{g}$ ) and 5NT (from $8 \cdot 8 \pm 2 \cdot 2$ to $125 \pm 5 \mathrm{IU} / 1$ ) and at 48 hours for GGT (from $1.42 \pm 0.25$ to $16.6 \pm 3.9$ IU/1). The administration of inhibitors of protein synthesis (cyclohexamide or actinomycin D) prevented the rise in both serum and hepatic values of ALP but did not affect the serum changes of 5NT and GGT.

These data suggest that increases in serum ALP, 5NT, and GGT are mediated by different processes. The relevance of these studies to clinical observations showing that 5NT and GGT are more sensitive than
ALP as markers of long-standing liver disease (Phelan et al, 1971; Whitfield et al, 1972) will be discussed.

\section{References}

Phelan, M. B., Neale, G., and Moss, D. W. (1971). Serial studies of serum alkaline phosphatase and 5'nucleotidase levels in hepatobiliary disease. Clin. chim. Acta, 32, 95.

Whitfield, J. B., Pounder, R. E., Neale, G., and Moss, D. W. (1972). Serum gamma glutamyltranspeptidase activity in liver disease. Gut, 13, 702.

\section{Controlled Trial of Corticosteroids and Azathioprine} in Active Chronic Hepatitis

R. B. STERN, I. M. MURRAY-LYON, AND R. WILLIAMS (Liver Unit, King's College Hospital Medical School, London) Active chronic hepatitis is usually a progressive disease with a mortality in untreated cases of at least $50 \%$ within five years of diagnosis. Controlled trials have shown that the prognosis is improved by treatment with corticosteroids, though side effects are frequent and often serious. In 1968 we decided to compare treatment with corticosteroids with azathioprine because results suggested that immunosuppressive drugs offered a useful alternative.

Fifty patients have been randomly allocated to two groups-one receiving prednisone $15 \mathrm{mg}$ daily and the other receiving azathioprine $75 \mathrm{mg}$ daily. At entry into the trial the groups were similar with respect to clinical, biochemical, and immunological features. When the trial was terminated most patients had had at least two years' treatment and by this time significant differences had emerged. One patient on prednisone and six on azathioprine had died. Actuarial analysis showed the probability of surviving two years was $95 \%$ on prednisone and $72 \%$ on azathioprine. Oesophageal varices developed in significantly more patients on azathioprine than on prednisone, and all six patients who bled during the trial period were on azathioprine. Liver function tests improved in both groups but the fall in serum gamma globulin in the prednisone group was significantly greater. Serious side effects developed in $32 \%$ of the patients on prednisone, and, although there was no definite evidence of azathioprine toxicity, it is not a satisfactory alternative to prednisone.

Cell-mediated Immunity in Primary Biliary Cirrhosis

R. N. M. MACSWEEN, I. GALBRAITH, G. B. LUDLAM, AND G. WATKINSON (University of Glasgow, Departments of Pathology and Medicine, Western Infirmary, Glasgow, 
and the Public Health Laboratories, Leeds) Evidence in vivo of impaired delayed hypersensitivity has been reported in primary biliary cirrhosis (PBC) (Fox et al, 1969). In addition diminished lymphocyte transformation in response to phytohaemagglutinin (PHA) currently regarded as in-vitro evidence of depressed thymus dependent ' $T$ ' cell function and therefore of impaired cell-mediated immunity-has been reported (Fox et al, 1969; Pettigrew et al, 1972) using a single dose stimulation technique with autologous serum. In the present study dose/response PHAinduced lymphocyte transformation (Fitzgerald, 1971) studies with homologous serum have been performed in a series of PBC patients. Impaired lymphocyte responsiveness, particularly with low doses of PHA, have been demonstrated, and are unrelated to the clinical state of the disease. These findings, together with the results obtained on serological screening for Toxoplasma gondii antibodies in a larger series of patients, provide conclusive evidence of impaired cell-mediated immunity in PBC.

\section{References}

Fitzgerald, M. G. (1971). Clin. exp. Immunol., 8, 421.

Fox, R. A., James, D. G., Scheuer, P. J., Sharma, O., and Sherlock, S. (1969). Lancet, 1, 959.

Pettigrew, N., Goudie, R. B., Russell, R. I., and Chaudhuri, A. K. R. (1972). Lancet, 2, 724.

Cell-mediated Immunity to Human Bile Proteins in Primary Biliary Cirrhosis

A. L. W. F. EDDI.eSTON, I. MACFARLANE, C. G. MITCHELL, W. D. REED, AND R. WILLIAMS (The Liver Unit, King's College Hospital and Medical School, London) We have previously demonstrated that more than $60 \%$ of patients with active chronic hepatitis show cell-mediated immune responses to a liver-specific lipoprotein which is probably a normal constituent of the hepatocyte cell membrane. In primary biliary cirrhosis, similar sensitization is found, though less frequently, and we suggested that the initial immune attack might be directed at antigens on the surface of bile duct epithelial cells. The possibility that such antigens could be present in normal bile prompted the present study.

Hepatic bile, collected from a T tube after cholecystectomy, was fractionated by gel filtration on Sephadex G 75, and the excluded portion, containing most of the bile proteins of higher molecular weight, was used as antigen in a micro-modification of the leucocyte migration test. Eight of 10 patients with primary biliary cirrhosis showed significant inhibition of leucocyte migration with the bile protein antigen. In the patients studied to date with extrahepatic biliary obstruction, no sensitization to the bile proteins has been detected.

The relation of this response to duration and stage of disease and the nature of the biliary antigen are the subjects of continuing studies, but the present study demonstrates, for the first time, the occurrence of cell-mediated immunity to bile antigens in primary biliary cirrhosis.

An Assessment of the Capacity of the Liver to Remove Antigen from the Portal Circulation in Normal and Cirrhotic Rats

H. C. THOMAS AND R. N. M. MACSWEEN (University of Glasgow, Departments of Bacteriology and Immunology, and Pathology, Western Infirmary, Glasgow) Immunogenic macromolecules of dietary and bacterial origin are absorbed from the alimentary tract and enter both the mesenteric lymphatics and portal capillaries (Warshaw et al, 1971). Oral immunization reduces the amount of antigen absorbed but significant quantities still enter the mesenteric lymph and portal blood (Walker et al, 1972). In this investigation the liver's capacity to remove antigen and immune complexes from the portal circulation has been studied.

The liver's capacity to remove antigen was found to be much increased by immunization. There was significantly more antigen retained in the liver after injection into the mesenteric vein than after injection of the same quantity of antigen into the femoral vein. This increased hepatic uptake after injection into the mesenteric vein was only demonstrated in immune animals and it is suggested that a low level of immunization to food and intestinal bacterial antigens is necessary for efficient removal of these antigens from the portal circulation. This antibody, if formed in the spleen, would enter the portal circulation directly and immune complexes would be formed in the portal vein. The liver was shown to be particularly efficient in removing immune complexes from the portal blood.

Similar studies have been made in rats rendered cirrhotic by inhalation of carbon tetrachloride and ingestion of phenobarbitone.

References

Walker, W. A., Isselbacher, K. J., and Bloch, K. J. (1972). Science, 177, 608-610.

Warshaw, A. L., Walker, W. A., Cornell, R., and Isselbacher, K. J. (1971). Lab. Invest., 25, 675.

Serum Ferritin as a Measure of Body Iron in Primary Idiopathic Haemochromatosis

R. J. WALKER, M. R. BEAMISH, A. JACOBS, AND R. williams (Liver Unit, King's College Hospital, 
London, and Department of Haematology, Welsh National School of Medicine, Cardiff) Direct measurement of total body iron stores has previously only been possible by the technique of repeated phlebotomy. This is tedious and only provides a retrospective answer. An indirect assessment may be made using chelating agents such as desferroxamine, but these tests are not reliable at lower levels of iron stores and in secondary iron overload.

Recently Jacobs and his colleagues (1972) have shown that the serum ferritin, measured by a sensitive radioimmunoassay, may give a quantitative assessment of storage iron both in normal subjects and in those with iron deficiency or overload. In the present study we have examined this relationship in a larger group of 29 patients with haemochromatosis. In seven untreated patients the initial levels varied from 1200 to $5040 \mu \mathrm{g} / \mathrm{ml}$ with a mean of $2795 \mu \mathrm{g} / \mathrm{ml}$. In three patients treated in the past and allowed to reaccumulate iron, the level varied from 55 to 660 $\mu \mathrm{g} / \mathrm{ml}$ with a mean of $312 \mu \mathrm{g} / \mathrm{ml}$. In these 10 patients serial measurements during venesection therapy showed a progressive decline in serum ferritin and bore a direct relationship with the amount of iron removed. Estimation of the serum ferritin may prove to be valuable both in the diagnosis of patients with iron overload and in following the effect of treatment on the iron stores.

\section{Reference}

Jacobs, A., Miller, F., Worwood, M., Beamish, M. R., and Wardrop, C. A. (1972). Brit. med. J., 4, 206.

The Relation between Liver Iron Concentration and Liver Damage in Transfusional Iron Overload in Thalassaemia and the Effect of Chelation Therapy

R. ANTHONY RISDON, DAVID M. FLYNN, AND MICHAEL BARRY (Department of Morbid Anatomy and Medicine, The Hospital for Sick Children, Great Ormond Street, and the Department of Medicine, Royal Free Hospital, London) It is generally accepted that longstanding iron overload produces a fibrogenic reaction in the liver which may progress to cirrhosis. Although both iron concentration and time may be important in the pathogenesis of liver injury little is known about the interplay of these factors. As part of a controlled study of long-term chelation therapy in children with thalassaemia, liver iron concentration was determined chemically and the severity of hepatic fibrosis graded histologically by independent observers in 52 liver biopsies obtained from 19 subjects over a seven-year period. The severity of the hepatic injury showed a general correlation with both iron concentration and with age; the correlation with age was particularly good in subjects not given chelation therapy. Fibrosis showed little or no progression in chelator-treated patients despite liver iron concentrations in the haemochromatosis range. Fibrosis was progressive in the control patients, severe damage and cirrhosis developing during the second decade of life. The results underline the importance of time as well as iron concentration in the pathogenesis of ironinduced liver injury but demonstrate that continuous chelation therapy reduces iron accumulation and delays hepatic damage.

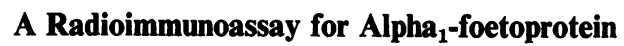

J. A. ChaYVIALle AND P. C. GANGUli (University Department of Surgery and Clinical Division of Gastroenterology, Royal Infirmary, Manchester) Alpert et al (1971) detected alpha ${ }_{1}$-foetoprotein (AFP) by immunodiffusion in $50 \%$ of the serum of 62 Caucasian patients with primary hepatocellular cancer of the liver. However, when these same samples were assayed by the more sensitive technique of counterimmunoelectrophoresis, the test was positive in $72 \%$ of the cases.

We have developed a sensitive, specific, and precise radioimmunoassay for AFP using reagents generously donated by Ruoslahti and Seppälä (1972). The highly purified antigen was labelled by the chloramine-T method. Alpha ${ }_{1}$-foetoprotein antiserum was raised in a sheep. Separation of antibodybound from free AFP was performed using a double-antibody method (Hunter and Ganguli, 1971).

Using this assay, AFP was measurable in all the plasma specimens taken from 100 control subjects, (range: $0 \cdot 25-15.0 \mathrm{ng} / \mathrm{ml}$ ). The AFP concentration was within the normal range in all the 10 patients with secondary neoplastic deposits in the liver, but in three cases of primary hepatoma the plasma AFP level was increased one-hundred fold or more above the upper limit of normal.

\section{References}

Alpert, E. Hershberg, R., Schur, P., and Isselbacher, K. J. (1971). Gastroenterology, 61, 137-143.

Hunter, W. M., and Ganguli, P. C. (1971). In Radioimmunoassay Workshop, edited by K. E. Kirkham and W. M. Hunter, pp. 243-257. Churchill-Livingstone, London.

Ruoslahti, E., and Seppälä, M. (1972). Nature (Lond.), 235, 161-162.

Treatment of Ascites by Continuous Ultrafiltration and Reinfusion of Protein Concentrate

S. P. PARBhoo, A. AJdukIEWICZ, AND S. SHERLOCK (Department of Medicine, Royal Free Hospital, London) During the past year an automated ultrafiltration device (Rhodiascit, Rhone Poulenc) has 
been evaluated in the treatment of massive ascites associated with chronic liver disease. The ultrafilter removes fluid and crystalloids with a molecular weight lower than 50000 and concentrates protein two- to four-fold. The aspiration rate, concentration, and reinfusion rate can be varied. Six females and 11 males aged 18-69 years were treated during 20 sessions lasting between three and 23 hours (average 9.7 hours). The associated hepatic lesion was alcoholic cirrhosis in six, post-hepatic or cryptogenic cirrhosis in seven, cirrhosis with active chronic hepatitis in two, and carcinoma of the liver and alcoholic hepatitis, each in one patient. The majority had received diuretic therapy and a number had diuretic-resistant ascites. Weight loss during the procedure was $14.4 \mathrm{lb}(5-41 \mathrm{lb})$ with production of $4100 \mathrm{ml}(400-8100 \mathrm{ml})$ of ultrafiltrate. A modest decrease of blood urea, increase in serum proteins, and a diuresis occurred in the majority of patients. One patient produced $5200 \mathrm{ml}$ of urine over 24 hours following treatment. The procedure was well tolerated, mild fever being the only consistent side effect.

Our experience has confirmed the efficacy and safety of this device. It may be of special value in the management of ascites in the alcoholic patient.

\section{The Epigastric Pain in Duodenal Ulcer}

J. B. DILAWARI, L. M. BLENDIS, AND D. A. W. EDWARDS (MRC Gastroenterology Unit, Central Middlesex Hospital, London) It has recently been suggested that central epigastric pain of duodenal ulcer is related to hypersensitivity of the lower oesophageal mucosa to acid (Earlam, 1970, 1972) and it has also been claimed that these patients have a lower cardiac sphincter pressure, and by implication an incompetent antireflux mechanism. We have failed to confirm these suggestions in a study of 27 patients with duodenal ulcer who were complaining of central epigastric pain.

Perfusion of the lower oesophagus with $0 \cdot 1 \mathrm{~N} \mathrm{HCl}$ reproduced the pain in only seven of the 27 patients. The mean volume of acid required to reproduce this pain was $77 \mathrm{ml}$ (range $35-140 \mathrm{ml}$ ) and the average time was 11 minutes (range 5-20 minutes).

The mean cardiac sphincter pressure in this group of 27 patients was $13.22 \mathrm{~mm} \mathrm{Hg}(\mathrm{SD} \pm 6.03)$ compared with $17.23 \mathrm{~mm} \mathrm{Hg}$ (SD $\pm 6: 29)$ in 17 controls. In the seven patients with the positive perfusion test the mean sphincter pressure was $13.85 \mathrm{~mm} \mathrm{Hg}(\mathrm{SD} \pm$ $8 \cdot 82)$ compared with $13.00 \mathrm{~mm} \mathrm{Hg}(\mathrm{SD} \pm 5.00)$ in the remaining 20 .

A radiological abnormality (hiatal hernia or reflux) was found in seven of the 27 patients, but only two of seven patients had a positive perfusion test.

Endoscopy was performed in five of the seven patients with a positive perfusion test but no abnormality was seen at the gastrooesophageal junction.

In summary, perfusion of the lower oesophagus with acid reproduced the central epigastric pain in only a minority of patients with duodenal ulcer. The cardiac sphincter pressure was normal and there was no greater incidence of radiological abnormality of the gastrooesophageal junction in these patients compared with patients with a negative perfusion test.

\section{References}

Earlam, R. J. (1970). Brit. med. J., 4, 714. Earlam, R. J. (1972). Brit. med. J., 2, 683.

\section{The Effect of Carbenoxolone on Ion Fluxes in} Denervated Fundic Pouches

M. R. THOMPSON, J. B. ELDER, AND I. E. GILLESPIE (University Department of Surgery, Manchester Royal Infirmary) Carbenoxolone has been shown to influence the rate of healing of gastric ulcers (Doll et al, 1962) but detailed knowledge of its mode of action is unknown. Davenport (1970) showed that damage to the gastric mucosa resulted in changes in hydrogen ion fluxes and suggested that this was important in the aetiology of gastric ulcers.

We have studied, in three dogs with denervated fundic pouches, the effect of instillation of carbenoxolone solutions on hydrogen, sodium, potassium, and chloride ion fluxes.

Carbenoxolone was dissolved in a phosphate buffer at $\mathrm{pH} 7.4$ in three concentrations $0.1 \mathrm{~g}, 0.5 \mathrm{~g}$, and $1.0 \mathrm{~g} /$ litre.

Using an acid solution containing $100 \mathrm{~m}$-equiv/ litre of $\mathrm{HCl}$ and $54 \mathrm{~m}$-equiv/litre of $\mathrm{NaCl}$, ion fluxes were measured before and after instillation for one hour of carbenoxolone solutions and of phosphate buffer alone.

In all control periods there was a net loss of hydrogen ions and a net gain of sodium ions.

One and a half hours after the buffer solution alone, hydrogen fluxes were $96 \%$ of control values. After the $0.1 \mathrm{~g}$ and $1.0 \mathrm{~g} /$ litre concentrations of carbenoxolone, hydrogen ion fluxes were reduced significantly to $63 \%$ and $66 \%$ of the control values respectively $(\mathrm{P}<0.05)$.

Thirty minutes after buffer alone there was an increase of $73 \%$ in sodium ion flux compared with control. After $0.5 \mathrm{~g}$ and $1.0 \mathrm{~g} /$ litre carbenoxolone there was a $124 \%$ and $165 \%$ increase in sodium ion fluxes respectively ( $\mathrm{P}<0.025$ and $\mathrm{P}<0.05)$. 
These results suggest that carbenoxolone significantly reduces hydrogen ion and increases sodium ion flux in fasting canine fundic mucosa.

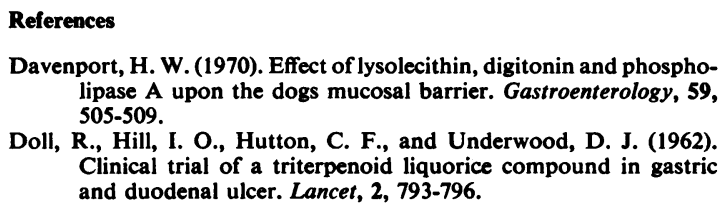

Davenport, H. W. (1970). Effect of lysolecithin, digitonin and phospholipase A upon the dogs mucosal barrier. Gastroenterology, 59, 505-509.

Doll, R., Hill, I. O., Hutton, C. F., and Underwood, D. J. (1962). Clinical trial of a triterpenoid liquorice compound in gastric and duodenal ulcer. Lancet, 2, 793-796.

\section{Strengthening the Gastric Mucosa}

B. CALCRAFT, J. RHODes, S. CROSS, AND D. HOLE Although carbenoxolone accelerates healing of gastric ulcer, its use is limited by side effects. BX-24 (lauroylglycerrhetic acid) is closely related to carbenoxolone and is said to be free from side effects. Bile reflux is an important factor in damaging gastric mucosa and compounds which protect against such damage may be of therapeutic value. We have used four dogs with Heidenhain pouches to examine whether carbenoxolone and BX-24 would protect gastric mucosa against bile damage. The net fluxes of $\mathrm{n}^{+}$and $\mathrm{Na}^{+}$in the pouch were measured for three consecutive 30-minute periods; before (1), during (2), and after (3) contact with either a $10 \mathrm{mM}$ solution of bile at $\mathrm{pH} 2$ or a similar control solution which did not contain bile. Each experiment was repeated three times in each dog. $\mathrm{H}^{+}$back diffusion from and $\mathrm{Na}^{+}$gain by the pouch were increased in periods 2 and 3 by the bile. When the pouch was prepared for one hour before each experiment with either a $0.33 \%$ solution of carbenoxolone or a $1 \%$ suspension of BX-24, the normal increase in back diffusion of $\mathrm{H}^{+}$after exposure to bile was significantly diminished ( $\mathrm{P} 0.001$ ), although $\mathrm{Na}^{+}$gain occurred as before.

The findings support the conclusion that these compounds protect gastric mucosa against bile damage, which may account for their effect in gastric ulcer.

Effect of Carbenoxolone Sodium upon Ionic Movement across the Gastric Mucosa in Patients with Gastric Ulcers

D. G. COLIN-JONES AND J. V. TAYLOR The gastric mucosa presents a barrier to ionic movements across it, both when normal and abnormal (Chapman et al, 1968). We studied gastric ionic movement in 13 patients with benign type 1 gastric ulcers before and after treatment with carbenoxolone. Using the method of Chapman et al (1968) three instillations of $200 \mathrm{ml}$ of isotonic $\mathrm{HCl}$ (160 m-equiv/ 1) with phenol red as a marker were made at each test, and means taken for fluxes of $\mathrm{H}^{+}, \mathrm{Cl}^{-}, \mathrm{Na}^{+}, \mathrm{K}^{+}$, volume secreted and theoretical non-parietal cell component. Each test was carried out immediately before starting carbenoxolone, one week later, one month later, and then one month after stopping treatment if the ulcer healed.

In eight patients the ulcer healed. The $\mathrm{H}^{+}$movement from lumen to blood diminished from -3.58 $\pm 1.50 \mathrm{~m}$-equiv/ $15 \mathrm{~min}$ before treatment to $-2.47 \pm$ 0.61 after one month $(P=0.2)$. This reduction was maintained one month after stopping treatment $(-2.46 \pm 0.94)$. The $\mathrm{Na}^{+}$fluxes from blood to lumen diminished also from $+4.68 \pm 0.91$ m-equiv/ 15 min to $3.39 \pm 0.62(P<0.05)$. In the five patients whose ulcers did not heal, the initial $\mathrm{H}^{+}$fluxes were lower (not significantly) and did not change ( -2.26 \pm 0.69 to $-2.32 \pm 1.66$ at one month), but the initial $\mathrm{Na}^{+}$fluxes were significantly reduced in the failed treatment group $(+4.68 \pm 0.91$ and $2.30 \pm$ $0.89, \mathrm{P}<0.01$ ). Carbenoxolone appears to decrease ionic movement across the gastric mucosa under the test conditions described, an effect that is continued after stopping treatment. Patients whose ulcers did not heal showed lower pretreatment ionic movements.

\section{Reference \\ Chapman, M. A., Werther, J. L., and Janowitz, H. D. (1968). Response of the normal and pathological human gastric mucosa to an instilled acid load. Gastroenterology, 55, 344.}

\section{A Study of the Role of Bile Acids in the Pathogenesis of Postvagotomy Diarrhoea}

J. G. ALLAN, V. P. GERSKOWITCH, AND R. I. RUSSELL (Department of Gastroenterology, Royal Infirmary, Glasgow) The pathogenesis of the diarrhoea which occurs in $20 \%$ of patients following vagotomy and drainage operations remains unknown (Williams and Cox, 1969).

Excessive amounts of dihydroxy bile acids in the colon have been shown to stimulate water and electrolyte secretion and cause diarrhoea (Mekhjian et al, 1971). The role of bile acids in causing postvagotomy diarrhoea has been evaluated by measuring their faecal excretion in patients with severe, continuous postvagotomy diarrhoea, patients with vagotomy and drainage operations but no diarrhoea, and in normal control subjects.

Seven subjects with postvagotomy diarrhoea were studied: all had operations one to eight years before the study and continuous watery diarrhoea (three to 12 motions daily) dating from the operation. Three 
had increased daily faecal fat excretion but all had normal jejunal mucosal histology.

The faecal bile acid excretion was measured by gas-liquid chromatography. The mean total faecal bile acid excretion measured over five days in patients with postvagotomy diarrhoea was $2099 \pm 474$ (SE) $\mathrm{mg}$ /day (range 958-3887 $\mathrm{mg}$ ). These results are significantly higher than those in the normal control subjects (mean $688 \pm 125$ ) $\mathrm{mg} /$ day: range 491 920: $\mathrm{P}<0.025$ ).

The mean daily faecal excretion of individual bile acids in the postvagotomy diarrhoea group and normal control subjects were cholic acid $389 \mathrm{mg}$ (control group $16 \mathrm{mg}$ ), deoxycholic acid $717 \mathrm{mg}$ $(365 \mathrm{mg})$, chenodeoxycholic acid $395 \mathrm{mg}(124 \mathrm{mg})$, and lithocholic acid $523 \mathrm{mg}(182 \mathrm{mg})$.

These results suggest that excessive amounts of bile acids in the colon (notably dihydroxy) may be a factor in the pathogenesis of severe continuous postvagotomy diarrhoea in some patients.

References

Mekhjian, H. S., Philips, S. F., and Hofmann. A. (1971). Colonic secretion of water and electrolytes induced by bile acids: perfusion studies in man. J. clin. Invest., 50, 1569-1577.

Williams, J. A., and Cox, A. (1969). After Vagotomy. Butterworth, London.

Inhibition of Gastric Secretion in Man by Metiamide: A New, Orally Active Histamine $\mathbf{H}_{2}$-receptor Antagonist

J. H. WYLLIE, WENDY D. P. EALDING, T. HESSELBO, AND J. W. PLACK (Department of Surgery, University College Hospital Medical School, London, and The Research Institute, Smith, Kline \& French Ltd., Welwyn Garden City) Histamine $\mathrm{H}_{2}$-receptor antagonists are a new class of drugs which antagonize actions of histamine not blocked by conventional antihistaminics. Burimamide is the only $\mathrm{H}_{2}$-receptor antagonist described so far, and is effective in blocking histamine-stimulated gastric acid secretion (Wyllie et al, 1972). However, it is relatively inactive when given by mouth.

Metiamide, an analogue of burimamide, has been given intravenously to seven volunteers. Gastric acid secretion was stimulated by either histamine acid phosphate $\left(40 \mu \mathrm{g} \mathrm{kg}^{-1} \mathrm{~h}^{-1}\right)$ or pentagastrin $(6 \mu \mathrm{g}$ $\mathbf{k g}^{-1} \mathrm{~h}^{-1}$ ) and when a plateau had been achieved metiamide was infused intravenously to give measured plasma levels. Acid secretion was inhibited or abolished in all subjects and the $\mathrm{EC}_{50}$ was calculated as $3.26 \mu \mathrm{M} \pm 0.67 \mathrm{SEM}$, a potency about five times that of burimamide. Intestinal absorption was studied by giving $200 \mathrm{mg}$ of radiolabelled metiamide to eight volunteers and a mean peak plasma level of $5.7 \mu \mathrm{M}$ was achieved after half an hour. Experiments using two different isotopic species of metiamide indicated that absorption of the drug was complete.

These results show that metiamide is a potent drug which can produce marked inhibition of gastric secretion. It therefore has considerable potential in the treatment of peptic ulceration.

\section{Reference}

Wyllie, J. H., Hesselbo, T., and Black, J. W. (1972). Lancet, 2, 1117. 1120.

The Effect of Codeine Phosphate, Lomotil, and Isogel on Ileostomy Function

C. R. NEWTON (Research Department, St Mark's Hospital, London). Introduced by J. E. Lennard-Jones. This study was designed to test the effect of codeine phosphate, Lomotil and Isogel on ileostomy output in subjects living a normal life. Volunteers for the study were sought through the Ileostomy Association. The study consisted of two three-day collection periods on and off treatment. Each 24-hour collection was weighed, homogenized, and analysed for sodium, potassium, faecal fat, and faecal solids. Mouth to stoma transit times were compared on one of the three days, using 20 polythene shapes.

Codeine phosphate, $60 \mathrm{mg}$ three times daily, given to five subjects was associated with a reduction in the 24-hour ileostomy output of sodium from a mean of $131 \mathrm{~m}$-equiv to 99 m-equiv $(\mathrm{P}<0.05)$, potassium from $6.8 \mathrm{~m}$-equiv to $4.1 \mathrm{~m}$-equiv $(\mathrm{P}<0.05)$, and water from $937 \mathrm{~g}$ to $700 \mathrm{~g}(\mathrm{P}<0.05)$; sodium and potassium concentrations were unchanged, but the proportion of faecal solids rose $(P<0.05)$ with a corresponding change in the consistency of the effluent. The transit rate was slower in four of the five subjects on codeine phosphate, and a further two subjects withdrew from the trial with temporary intestinal obstruction while on the drug. Codeine phosphate was also associated with an increase in the faecal fat excretion from 6.1 to $9.6 \mathrm{~g}$ per 24 hours $(\mathrm{P}<0.05)$.

Lomotil, two tablets three times daily, given to five subjects was associated with a fall in the 24-hour ileostomy output of sodium from a mean of 85 m-equiv to 77 m-equiv $(P<0.05)$, potassium from $4.2 \mathrm{~m}$-equiv to $3.8 \mathrm{~m}$-equiv $(\mathrm{P}<0.05)$, and water from $623 \mathrm{~g}$ to $568 \mathrm{~g}(0.1<\mathrm{p}>0.05)$; there was no change in the concentrations of sodium and potassium or the proportion of faecal solids. None of the subjects tested experienced any intestinal symptoms on the drug. Transit rate on Lomotil was slower in two and more rapid in three of the ileostomists tested. Faecal fat was unaffected.

Isogel, $15 \mathrm{ml}$ three times daily, given to six subjects increased the viscosity of the effluent, but, contrary 
to popular belief, was associated with an increase in the 24-hour ileostomy output of sodium from a mean of 93 m-equiv to $125 \mathrm{~m}$-equiv $(\mathrm{P}<0.01)$, potassium from $4.7 \mathrm{~m}$-equiv to $6.7 \mathrm{~m}$-equiv $(\mathrm{P}<0.01)$, and water from $668 \mathrm{~g}$ to $898 \mathrm{~g}(\mathrm{P}<0.01)$; the concentrations of sodium and potassium and the proportion of faecal solids remained unchanged. Transit rate showed no consistent change. Faecal fat increased in four of the six subjects on Isogel.

These results suggest that codeine phosphate has a beneficial effect on ileostomy function, decreasing the loss of sodium, potassium, and water, but may precipitate intestinal obstruction. Lomotil in the dosage tested has a similar but less effective action. Isogel, by contrast, increases the loss of sodium, potassium, and water and will aggravate fluid and electrolyte depletion in patients with excessive ileostomy effluents. The increase in faecal fat excretion associated with taking both codeine phosphate and Isogel suggests that these substances should be stopped before collecting specimens for faecal fat estimations.

\section{Truncal Vagotomy and Drainage for Duodenal Ulcer}

C. MACKAY, F. KENNEDY, B. S. BEDI, AND A. W. KAY (University Department of Surgery, Western Infirmary, Glasgow) This paper presents the results of a prospective randomized trial of truncal vagotomy and pyloroplasty (204 patients) against truncal vagotomy and gastrojejunostomy (200 patients) for duodenal ulcer. One hundred and one patients excluded because of severe pyloroduodenal deformity, and 42 because they required a diagnostic pyloroduodenotomy, were also studied. Four hundred and fifty-four patients $(83 \%)$ were assessed at least two years after operation, the mean length of follow up being four years. All data were collected, stored and analysed using a specially designed computer system SWITCH.

The operative mortality was $0.5 \%$. Of this $88.6 \%$ were graded satisfactory (Visick 1 or 2 ) and $6.1 \%$ unsatisfactory (Visick 4). Fifteen patients $(3.3 \%)$ have required further surgery for recurrent ulceration. Troublesome dumping occurred in $2 \%$ and incapacitating diarrhoea in $0.9 \%$. Severe bilious vomiting occurred in $2 \%$. The only statistically significant difference between the groups was the incidence of bilious vomiting which occurred more commonly in the gastrojejunostomy groups.

Insulin testing performed seven to 10 days after operation was a useful index of likely recurrent ulceration; the incidence was $23.1 \%$ in patients with an early positive response, $5.5 \%$ in late positive, and $1.6 \%$ in insulin-negative patients.
It is considered that the results of truncal vagotomy and drainage are such that modification of the type of vagotomy can be expected togive, at best, marginal advantages.

\section{Effects of Oral Magnesium Sulphate on Colonic Motility}

R. F. HARVEY AND A. E. READ (From Bristol Royal Infirmary) Patients with 'functional' abdominal pain after food (Connell et al, 1965) have a marked intestinal motor response to cholecystokinin (CCK) (Harvey and Read, 1973), and this may be important in the production of their symptoms. To determine whether endogenous CCK has effects similar to those of the injected hormone, we have measured motor activity in the sigmoid colon after oral magnesium sulphate $\left(\mathrm{MgSO}_{4}\right)$, a powerful cholagogue (Boyden et al, 1973).

Twenty patients with abdominal pain believed to be due to the irritable bowel syndrome were studied. Ten had food-related pain, and in the other 10 there was no relationship of the pain with eating. Pressure changes in the sigmoid colon were measured using miniature balloons, as previously described (Harvey and Read, 1973), for three consecutive 30-minute periods, fasting, after $150 \mathrm{ml}$ water, and after $\mathrm{MgSO}_{4}$ $(0.1 \mathrm{~g} / \mathrm{kg}$ in $150 \mathrm{ml}$ water $)$ by mouth.

No significant change in motor activity was seen after water, but all parameters measured showed an increase after $\mathrm{MgSO}_{4}$ ( $\%$ activity 16.2 to 23.7 , $\mathbf{P}<0.05$; mean amplitude of pressure waves 7.1 to $9.1 \mathrm{~cm}$ water, $0.05<\mathrm{P}<0.10$; motility index 144 to $259, \mathrm{P}<0.01)$. The increase was most marked in the 10 patients whose pain was usually precipitated by eating $(16.1$ to $29.8 \%, \mathrm{P}<0.01 ; 6.8$ to $9.6 \mathrm{~cm}$ water, $\mathrm{P}<0.05 ; 135$ to $350, \mathrm{P}<0.025)$ and three of these patients experienced an attack of their usual pain after $\mathrm{MgSO}_{4}$.

These results provide further evidence that the abnormally increased postprandial colonic motor activity in patients with 'functional' food-induced pain (Connell et al) may be mediated by endogenous cholecystokinin. They also suggest that the purgative action of $\mathrm{MgSO}_{4}$ may in part be due to increased intestinal motor activity resulting from CCK release.

References

Boyden, E. A., Bergh, G. S., and Layne, J. A. (1943). An analysis of the reaction of the human gall bladder and sphincter of Oddi to magnesium sulfate. Surgery, 13, 723-729.

Connell, A. M., Avery Jones, F., and Rowlands, E. N. (1965). Motility of the pelvic colon. IV. Abdominal pain associated with colonic hypermotility after meals. Gut, 6, 105-112.

Harvey, R. F., and Read, A. E. (1973). Effect of cholecystokinin on colonic motility and symptoms in patients with the irritablebowel syndrome. Lancet, 1, 1-3. 
Urinary Homovanillic Acid (HVA) Excretion in Cases of Diarrhoea of Presumed Nervous Origin

J. T. WRIGHT AND A. K. DAS (Department of Gastroenterology, The London Hospital) In the course of an earlier study (Wright and Das, 1969) on the urinary excretion of vanillylmandelic acid (VMA) in patients with diarrhoea of presumed nervous origin we observed but did not document an apparent increase in the excretion of homovanillic acid (HVA) which is the end product of dopamine metabolism equivalent to VMA in adrenergic metabolism.

In the present work 10 female and eight male patients suffering from chronic diarrhoea of presumed nervous origin were studied. Controls matched for age and sex were selected from a duodenal ulcer population attending the same morning gastroenterological clinic. Urine was collected at the second visit and its HVA (Ruthven and Sandler, 1966), VMA (Connellan and Godfrey, 1964) and creatinine content estimated.

The mean urinary HVA excretion of the patients with nervous diarrhoea $(8.36 \pm \mathrm{SE} \quad 1.31 \mathrm{mg} / \mathrm{g}$ creatinine) was significantly higher than that of the control group $(3.86 \pm 0.342 \mathrm{mg} / \mathrm{g}$ creatinine, $\mathrm{P}<$ $0.01)$. The VMA was slightly, but not significantly raised in the former group.

These results imply an increase in dopamine metabolism in nervous diarrhoea. The role of dopamine in neurotransmission is still uncertain; convention confines it to the central nervous system and it would not be surprising if the increased excretion of HVA in our subjects reflected central action. On the other hand, there is increasing evidence that dopamine is involved in the peripheral autonomic system and our results equally well suggest increased peripheral autonomic activity in these patients.

References

Connellan, T. P., and Godfrey, J. M. (1964). The routine determination of urinary 4-hydroxy-3 methoxy mandelic acid. Clin. chim. Acta, 9, 410 .

Ruthven, C. R. J., and Sandler, M. (1966). An improved method for the estimation of homovanillic acid in human urine. Clin. chim. Acta, 14, 511.

Wright, J. T., and Das, A. K. (1969). Excretion of 4-hydroxy-3 methoxy mandelic acid in cases of ulcerative colitis and diarrhoea of nervous origin. Gut, 10, 628.

Colonoscopy in the Investigation of Ulcerative Colitis

J. B. DILAWARI, CONSTANCE PARKINSON, R. H. RIDDELL, H. LOOSE, AND CHRISTOPHER WILLIAMS (MRC Gastroenterology Unit, Central Middlesex Hospital, London and St Marks Hospital, London) We have examined 80 patients with ulcerative colitis using the colonoscope and have compared colonoscopic with histological and radiological observations. In 44 patients the whole colon was examined and multiple biopsies were taken in order to assess the extent of disease. In the majority of cases the endoscopic and radiological findings were in agreement but in six patients endoscopy showed more extensive disease than did radiographs and in a further eight patients the histology showed more extensive abnormality than either endoscopy or radiographs.

Of 17 strictures demonstrated radiologically, only seven were apparent at colonoscopy, but none showed histological evidence of malignant change. In two of eight patients with precancerous change in the rectal mucosa biopsies from the proximal colon showed precancer. There was no evidence of precancer in 360 biopsies from sites throughout the colon in 24 patients with total colitis of more than 10 years' duration.

The conclusion from this series is that in selected patients with ulcerative colitis colonoscopy can provide useful information. In some of our patients colonoscopy and multiple biopsy have revealed extensive disease not visible on barium enema. In others the endoscopic and histological findings have supported the continued medical management of patients with chronic extensive disease, some of them with apparent strictures or other radiological abnormalities.

\section{Pharmacokinetics and Azo-link Cleavage of Salazo- pyrine in Man}

R. M. LEWKONIA, H. SCHRÖDER, AND D. A. PRICE EVANS (Department of Medicine, University of Liverpool, and Pharmacia AB, Uppsala, Sweden) A comparative study of the metabolism of salicyl-azosulphapyridine (salazopyrine) has been undertaken in 26 healthy volunteers, 19 patients with colitis of varying severity, and 10 ileostomized subjects. The serum levels and urinary excretion of salazopyrine metabolites were similar in normal individuals and patients with colitis.

The urinary excretion of intact salazopyrine was similar in the three groups studied and was $2.8 \pm$ $0.6 \%$ of the dose (mean $\pm 95 \%$ confidence limits). Subjects with an intact colon excreted $60.5 \% \pm$ $4.3 \%$ of the dose in the urine as sulphapyridine metabolites (which are formed after azo-link cleavage) whereas the comparable figure for ileostomized subjects was $7 \cdot 1 \% \pm 6 \cdot 8 \%$.

Following phenobarbitone administration the urinary excretion of salazopyrine was reduced by approximately $18 \%$, but the excretion of the primary metabolite sulphapyridine was unchanged. Phenobarbitone had no significant effect on the pharmaco- 
kinetics of salazopyrine cleavage in ileostomized subjects. These results suggest that the colon is the site of azo-link cleavage of salazopyrine in man and that phenobarbitone-inducible enzymes do not have any major role in the cleavage. This confirms work in conventional and germ-free rats (Schröder and Gustafsson, 1973; Peppercorn and Goldman, 1972) which has shown that the microflora of the distal gut is necessary for significant azo-link cleavage to occur.

The therapeutic effects of salazopyrine may be due to the intracolonic release of sulphapyridine or 5 -amino-salicylic acid in high concentrations. It may be that high concentrations in the colonic mucosa cannot readily be achieved by oral medication with these primary metabolites because they are absorbed in the small bowel (Schröder and Campbell, 1972).

\section{References}

Peppercorn, M. A., and Goldman, P. (1972). The role of intestinal bacteria in the metabolism of salicyl-azo-sulphapyridine. $J$. Pharmacol. exp. Ther., 181, 55-562.

Schröder, H., and Campbell, D. E. S. (1972). Absorption, metabolism and excretion of salicyl-azo-sulfapyridine in man. Clin. Pharmacol. Ther., 13, 539-551.

Schröder, H., and Gustafsson, B. E. (1973). Azo reduction of salicylazo-sulfapyridine by germ-free and conventional rats. Zenobiotica, in press.

\section{A New Procedure for the Study of Malabsorption and Chronic Diarrhoea of Undetermined Aetiology in Infancy and Childhood}

R. NELSON, G. M. MURPHY, S. EDKINS, J. M. RICHARDSON, AND C. M. ANDERSON A comprehensive test of pancreatic function, bile salt metabolism, and the bacterial flora of the small intestine, which requires a single duodenal intubation has been developed.

\section{METHOD}

Intubation of the duodenum and stomach was performed after a fast of over five hours. Duodenal fluid was collected for $\mathbf{3 0}$ minutes fasting, for $\mathbf{3 0}$ minutes after intravenous pancreozymin, and for a further $\mathbf{3 0}$ minutes after secretion. Two hours after pancreozymin, a test meal of measured composition, containing $1 \mathrm{~g}$ fat $/ \mathrm{kg}$ body weight, was instilled directly into the stomach. Duodenal contents were then collected for 60 minutes.

\section{ANALYSES}

(i) Pancreatic function-duodenal pancreatic enzymes and bicarbonate concentrations were estimated fasting and after pancreozymin and secretin.

(ii) Bile acid metabolism: (a) serum bile acids measured fasting, and one hour after the meal; (b) duodenal bile acids measured on all samples; (c) 24-hour faecal fat and bile acid excretion measured following three-day collection; (d) 24-hour urinary bile acids determined if liver disease suspected, or serum bile acids elevated.

(iii) Bacteriology-aerobic and anaerobic bacterial flora of the nose, throat, stomach, and duodenum were studied.

The results of application of this procedure to patients with malabsorption and diarrhoea of unknown aetiology are presented, and their clinical value discussed.

\section{Postinfective Malabsorption: A Sprue Syndrome}

R. DARRAGH MONTGOMERY, D. J. BEALE, H. G. SAMMONS, AND R. SCHNEIDER (The Metabolic Unit, the East Birmingham Hospital, Birmingham) Thirteen cases are described of temporary malabsorption in adults, presenting in Britain after an acute episode of apparent infective enteritis. Clinical features included diarrhoea, anorexia, and weight loss in all cases, and steatorrhoea in the majority. Investigations indicated impairment of function in the small bowel including the ileum, with well preserved mucosal morphology in the upper jejunum and a tendency to folate depletion. Spontaneous recovery usually occurred within weeks, but two cases ran a more prolonged and severe course. There was no intolerance of gluten.

The relationship is discussed of this syndrome to tropical sprue and to unexplained megaloblastic anaemia in temperate countries.

\section{Tripeptide Absorption in Man}

D. B. A. SILK, D. PERRETT, JOAN P. W. WEBB, AND M. L. CLARK (Departments of Gastroenterology and Medicine, St Bartholomew's Hospital, London) Perfusion studies in man have shown that more efficient absorption of some amino acids occurs when they are perfused as dipeptides (Adibi, 1971). Nutritionally, however, absorption from larger peptides may be more important (Nixon and Mawer, 1970), and we have therefore used a double-lumen perfusion technique (Sladen and Dawson, 1970) in man to study the uptake of two larger peptides, glycylglycyl-glycine and L-alanyl-glycyl-glycine. Both tripeptides conferred a kinetic advantage on amino acid absorption as their constituent amino acids were all absorbed faster from the tripeptide solutions than from the equivalent amino acid solutions. Furthermore, the enhanced sodium and water absorption seen when the equivalent amino acid $\mathrm{m}$ ixture is perfused is abolished when alanyl-glycylglycine is perfused. 
Free alanine, glycine, and glycyl-glycine were seen in the intestinal aspirates obtained during perfusion of the tripeptides. Little alanyl-glycine was seen during alanyl-glycyl-glycine perfusion, indicating that preferential hydrolysis of the $\mathrm{N}$-terminal end of the molecule occurs during the transport process.

These findings suggest that the tripeptides are taken up by a mechanism independent of amino acid transport, the small amounts of free glycyl-glycine and amino acids seen during the perfusions being due to both intraluminal and brush border hydrolysis.

In conclusion, these perfusion studies emphasize the importance of peptide transport, and demonstrate that complete intraluminal hydrolysis of ingested protein need not take place before absorption.

\section{References}

Adibi, S. A. (1971). J. clin. Invest., 50, 2266-2275.

Nixon, S. E., and Mawer, G. E. (1970). Brit. J. Nutr., 24, 241-258.

Sladen, G. E., and Dawson, A. M. (1970). Gut, 11, 947-954.

Intestinal Absorption of Intact Dipeptides: Studies with Glycine and Glycyl Proline

R. C. HEADING AND H. P. SCHEDL (introduced by D. J. C. Shearman) (Gastrointestinal Section of the University Department of Therapeutics, Royal Infirmary of Edinburgh, and the Gastrointestinal Research Laboratory, Department of Internal Medicine, University of Iowa, Iowa City, USA) It has been suggested that hydrolytic activity against dipeptides which contain proline is absent from the intestinal brush border (Gray and Cooper, 1971), implying that their absorption occurs solely by transport of intact peptides.

We have perfused rat jejunal and ileal segments in vivo with ${ }^{3} \mathrm{H}$ glycine $\left({ }^{14} \mathrm{C}\right.$ glycyl), glycyl L proline, or equimolar mixtures of both at concentrations between 0.5 and $4 \mathrm{mM}$. Absorptions were determined from the fall in isotope content of the perfusion solutions.

Absorption rates of the amino acid and peptide were similar. Both were directly proportional to concentration and both were significantly greater in jejunum than in ileum. However, in the experiments in which absorption from a mixture of glycine and glycyl-proline was measured, the peptide was slightly more rapidly absorbed than the amino acid $(P<0.01)$. Neither substance had any apparent effect on absorption of the other.

The results demonstrate that at concentrations likely to be physiologically relevant, the absorption of glycyl-proline by both jejunum and ileum occurs at rates comparable with those of glycine. In contrast to the absorption of most other peptides it is likely that this is effected entirely by the transport of intact peptide.

Reference

Gray, G. M., and Cooper, H. L. (1971). Gastroenterology, 61, 535.

Acute Pancreatitis in Patients with Fulminant Hepatic Failure

S. P. PARBHOO, J. WELCH, AND SHEILA SHERLOCK (Department of Medicine, Royal Free Hospital, London) The development of scintiscanning, isoamylase electrophoresis, and new tests of pancreatic function has revived interest in pancreatitis associated with liver failure. Scattered case reports have documented this association but no large series has been published. In order to ascertain the incidence and nature of pancreatitis associated with acute hepatic failure we have reviewed the medical records and histological material of patients who died of fulminant hepatitis between 1960 and 1972. In addition a prospective study including serum amylase, amylase isoenzymes, pancreatic scintiscanning, and the Lundh test is in progress.

Necropsy sections were available on 59 patients (37 women and 22 men) aged 8-63 years (mean age 37). The major cause was viral hepatitis ( 42 patients); other causes included drugs, halothane, and fatty liver of pregnancy. Mild to diffuse haemorrhagic pancreatitis was seen in 21 patients. There was no correlation between the incidence of pancreatitis and aetiology of liver failure, steroid treatment, or extracorporeal liver perfusion.

The prospective survey comprised 60 patients (41 women and 19 men), half of whom had viral hepatitis. Fourteen of these patients had raised levels of serum amylase, 400-2000 iu/litre (mean 1020). Eleven of these patients came to necropsy and pancreatitis was present in 10 of them.

Pancreatitis is therefore commonly associated with acute hepatic failure but difficult to detect clinically. Further studies are required to investigate the nature of the relationship and possible cause.

\section{A Second Intestinal Glucose Carrier}

H. B. mcmichael (Middlesex Hospital, London) Although the existence of a second glucose carrier has been suggested (Crane et al, 1970), no direct systematic attempt has previously been made to define its characteristics. It has been studied using an in-vivo steady-state perfusion technique in anaesthetized rats (Dawson and McMichael, 1968). Since the transport characteristics for glucose are different in the jejunum and ileum (Rider et al, 1967), simul- 
taneous perfusions were carried out in these two regions with various potential inhibitors.

Glucose transport in the jejunum is little affected by the presence of galactose but is very sensitive to uranyl nitrate, and is biphasically inhibited by phlorizin. Transport in the ileum is significantly more inhibited by galactose, less inhibited by uranyl nitrate, and is inhibited monophasically by phlorizin.

These data suggest strongly that there are two glucose carriers with some selective location to different parts of the small intestine.

\section{References}

Crane, R. K., Malathi, P. et al (1970). Fed. Proc., 29, 595.

Dawson, A. M., and McMichael, H. B. (1968). J. Physiol. (Lond.), 196, 32p.

Rider A. K., Schedl, H. P., Nokes, G., and Shining, S. (1967). J. gen. Physiol., 50, 1171.

Evidence for Circulating Immune Complexes in Inflammatory Bowel Disease and Adult Coeliac Disease

WILLIAM F. DOE AND D. BROWN (Departments of Medicine and Immunology, Royal Postgraduate Medical School, London) We have previously reported mixed cryoglobulinaemia and vasculitis in association with adult coeliac disease (Doe $e t$ al, 1971) and recently circulating immune complexes have been observed in the sera of some Crohn's disease and ulcerative colitis patients (Jewell et al, 1972). Whether these complexes are capable of initiating tissue damage, however, is not known.

Sera from patients with adult coeliac disease, Crohn's disease, and ulcerative colitis were examined for the presence of soluble immune complexes capable of binding to the $C_{1 q}$ component of the complement system. The ability of purified $\mathrm{C}_{\mathbf{1 q}}$ to bind to certain immune complexes and precipitate them in agar gel was used as the test system (Agnello et al, 1970). Fifty-seven per cent of 20 Crohn's sera, $30 \%$ of 91 adult coeliac sera, and $20 \%$ of ulcerative colitis sera gave a positive reaction with $\mathrm{C}_{1 \mathrm{q}}$. Only one of 25 healthy controls' sera examined gave a positive result. When sera from coeliac patients taking a normal diet were compared to those taking a gluten-free diet a marked reduction in positive reactions from 40 to $10 \%$ was observed. This data suggest that complement-binding, soluble immune complexes are present in the sera of patients with adult coeliac disease and inflammatory bowel disease and could contribute to the pathogenesis of these diseases.

\section{References}

Agnello, V., Winchester, R. J., and Kunkel, H. G. (1970). Immunology, $19,909$.
Doe, William, F., Evans, D., Hobbs, J. R., and Booth, C. C. (1971)• Gut, 13, 319.

Jewell, D. P., MacClennon, I. C. M., and Truelove, S. C. (1972). Gut, $13,839$.

Cellular Infiltrate of Jejunal Biopsies in Adult Coeliac Disease (ACD) in Relation to Gluten Withdrawal

G. K. T. HOLMES, P. ASQUITH, P. L. STOKES, AND W. T. COOKE One characteristic feature of the abnormal jejunum found in ACD is the inflammatory cell infiltrate. It has been suggested that these cells are related to the pathogenesis of the lesion and this supports an immunological explanation for gluten toxicity.

Cells were classified and counted in the lamina propria and epithelium of jejunal biopsies from 12 controls and 11 patients with ACD on (a) a normal diet and $(b)$ following gluten withdrawal. The total and plasma cell counts in the lamina propria of normal diet patients were raised compared with controls. These counts fell after gluten withdrawal but were still abnormal. Changes in intraepithelial lymphocyte counts were similar. However, the numbers of lamina propria lymphocytes were reduced in untreated coeliacs but returned to normal on a glutenfree diet. There was a correlation between the fall in plasma cells and the rise in lamina propria lymphocytes and morphological improvement following gluten withdrawal.

Our observations suggest the abnormal mucosa seen in ACD in response to gluten is correlated more with an alteration in humoral rather than cellular immunity.

\section{Cytokinetic Diversity in the Flat Mucosa of 'Coeliac' Disease}

N. A. WRIGHT, A. J. WATSON, A. R. MORLEY, D. R. APPLETON, JANET M. MARKS, AND J. D. BELL (Departments of Pathology, Medical Statistics, Dermatology, and Child Health, University of Newcastle upon Tyne) Barry and Read (1972) suggested that patients with adult coeliac disease could be separated into two groups on the basis of measurements of smallintestinal mucosal-cell dynamics. One group showed low mitotic indices and epithelial cell-loss rates, while the other group showed high values for these parameters. These studies were correlated with subsequent response to a gluten-free diet.

We have studied mucosal-cell kinetics in small bowel biopsies of 75 adults and 10 children with morphologically normal mucosae, and pretreatment biopsies from 13 patients with adult coeliac disease, 29 with childhood coeliac disease, and 21 with 
dermatitis herpetiformis (all with flat mucosae). Of the latter groups, seven patients with adult coeliac disease, 14 with childhood coeliac disease, and seven with dermatitis herpetiformis showed mitotic indices falling within the normal range. Crypt cell production rates in these were smaller than in the remaining patients with high indices.

Booth (1970) and Wright et al (1972) concluded that a hyperproductive mucosal state is encountered in untreated coeliac disease; any unitary theory of the evolution of the coeliac mucosa must now take into consideration the significant number of patients in this larger series who show instead a normal cell production rate.

References

Barry, R. E., and Read, A. E. (1972). Two types of 'coeliac' disease. Gut, 13, 846-847.

Booth, C. C. (1970). The enterocyte. Brit. merl. J., 2, 725-729.

Wright, N. A., Watson, A. J., Morley, A. R., Appleton, D. R., Marks, J. M., and Douglas, A. (1972). Cell production rate in mucosa of untreated coeliac disease. Gut, 13, 846 .

Lysosomal Acid Hydrolase Activity in Intestinal Biopsies from Control Subjects and Patients with Coeliac Disease

T. J. PETERS, W. F. DOE, J. R. HEATH, AND J. D. MITCHELL (Department of Medicine, Royal Postgraduate Medical School, London) Ultrastructural and histochemical studies of enterocytes in patients with coeliac disease have suggested that there are morphological abnormalitities of the lysosomes in this disease. We have therefore initiated a study of this organelle in normal and pathological small intestinal mucosa. Using highly sensitive enzyme assays with fluorogenic substrates, the following acid hydrolases (pH optima between parentheses) were demonstrated in homogenates of normal intestinal mucosa: betagalactosidase (3.5), beta-glucuronidase (3.8), acid phosphatase (4.0), alpha-mannosidase (4.0), alphagalactosidase (4.0), $\mathrm{N}$-acetyl-beta-galactosaminidase $(5 \cdot 0)$, N-acetyl-beta-glucosaminidase $(5 \cdot 8)$, betaglucosidase (5.9). Latent $(70 \pm 5 \%)$ and sedimentable $(75 \pm 4 \%) \mathrm{N}$-acetyl-beta-glucosaminidaseclearly demonstrates the presence of intact lysosomes in this tissue. Assay of enzyme activity $(\mathrm{mU} / \mathrm{mg}$ protein) in biopsy samples from patients with untreated coeliac disease showed two- to threefold higher levels of these acid hydrolases compared with control samples. Alkaline phosphatase and other brush border enzymes showed a two- to fourfold decrease in specific activity. The ratio of alkaline phosphatase to $\mathrm{N}$-acetyl-beta-glucosaminidase in controls $(15.10 \pm 1.44)$ was strikingly higher than that in coeliac disease $(3.38 \pm 0.90$, $P>0.001$ ).

These observations provide further evidence that lysosomes may contribute to the pathogenesis of coeliac disease but further studies are necessary before their precise role can be ascertained. 